\title{
Abdome agudo: ruptura espontânea de bexiga como um importante diagnóstico diferencial
}

\section{Acute abdomen: spontaneous bladder rupture as an important differential diagnosis}

Carlos Augusto Gomes, tCBC-MG; André Avarese de Figueiredo²; Cleber Soares Júnior, TCBC-MG; José Murillo Bastos Netto ${ }^{4}$; Fabrício Rodrigues Tassi ${ }^{5}$

\section{INTRODUÇÃO}

A ruptura espontânea intraperitoneal de bexiga é rara e pode ter evolução grave e letal caso o diagnóstico e o tratamento precoce sejam omitidos ${ }^{1}$. O presente trabalho tem como objetivo relatar o caso de ruptura espontânea de bexiga com diagnóstico intra-operatório e má evolução clínica.

\section{RELATO DO CASO}

Mulher de 79 anos, diabética, com antecedente de infecção urinária de repetição e incontinência urinária, procurou o hospital com dor hipogástrica e febre há dois dias. Ao exame físico, apresentava com dor hipogástrica sem sinais de irritação peritoneal. Exames laboratoriais mostraram anemia, uréia sérica de $54 \mathrm{mg} / \mathrm{dl}$ e creatinina sérica de $1,3 \mathrm{mg} / \mathrm{dl}$, hematúria microscópica e urocultura positiva para E. coli.

A paciente evoluiu após 24 h com distensão abdominal, oligúria e sinais de sepse, sendo transferida para a Unidade de Terapia Intensiva. A tomografia computadorizada de abdome não evidenciou líquido livre peritoneal ou outras alterações significativas (Figura 1). Apesar da antibioticoterapia, houve piora progressiva do quadro séptico sendo indicado laparotomia exploradora, tendo como principal suspeita isquemia mesentérica. Durante o procedimento, foi evidenciado peritonite, com necrose e ruptura da cúpula vesical peritoneal bloqueada pelas alças de íleo. Foi então realizado desbridamento do tecido necrótico perivesical, cistostomia e rafia do segmento perfurado da bexiga. O exame histológico de segmento vesical próximo ao local da perfuração não mostrou doença maligna.

A paciente evoluiu com manutenção do quadro séptico a despeito das medidas clínicas adotadas, má evolução clínica e óbito no nono dia após o tratamento operatório.

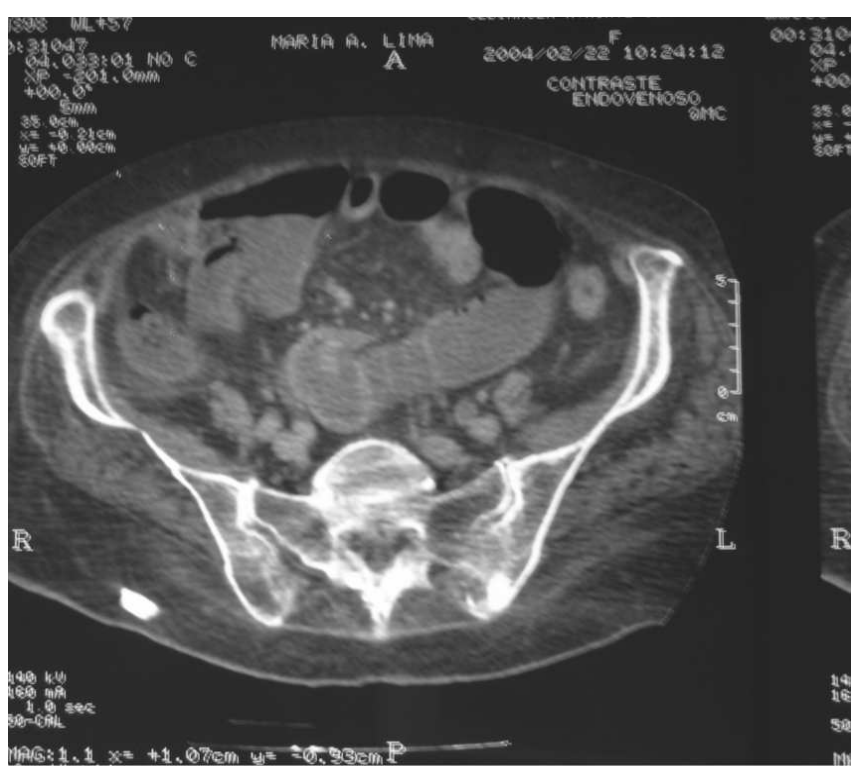

Figura 1 - Tomografia computadorizada de pelve mostrando distensão gasosa de alças intestinais e ausência de líquido livre intra-abdominal.

\section{DISCUSSÃO}

A ruptura espontânea de bexiga ocorre em pacientes com retenção urinária, diminuição da sensibilidade vesical, infecção urinária e isquemia da parede vesical, consequente ao aumento da pressão intravesical. Os mecanismos fisiopatológicos levam ao seu rompimento no ponto mais frágil, que, via de regra, é o segmento peritoneal ${ }^{1}$. Desta forma, pacientes com bexiga neurogênica, antecedentes de enterocistoplastia, após radioterapia pélvica e com tumores malignos de bexiga são os mais propensos ao desenvolvimento da complicação ${ }^{1}$. No presente caso, a paciente apresentava diabetes e antecedente de incontinência urinária. Na cistopatia diabética, ocorre diminuição da sensibilidade vesical e hipocontratilidade detrusora, provocando permanente alto resíduo pós- 
miccional e incontinência por transbordamento. A retenção urinária crônica e a infecção urinária podem ter sido os fatores que contribuíram pela ruptura vesical verificados nesta paciente. São também citados como fatores implicados na ruptura da bexiga, a ingestão alcoólica, por determinar alteração da sensibilidade vesical, poliúria com hiperdistensão vesical e maior suscetibilidade a pequenos traumas ${ }^{2}$.

Clinicamente, os pacientes com ruptura vesical apresentam dor abdominal difusa, mais intensa no andar inferior do abdome, ascite urinária, distensão abdominal, retenção urinária e oligúria ou anúria após cateterismo vesical $^{2}$. Uréia e creatinina estão aumentadas em $45 \%$ dos casos já nas primeiras $24 \mathrm{~h}$, e em praticamente $100 \%$ após $24 \mathrm{~h}$ de ruptura, com maior aumento da uréia pela sua maior absorção peritoneal ${ }^{3}$.

O método de imagem de escolha é a cistografia, que demonstra vazamento intraperitoneal do contraste. A acurácia é próxima de $100 \%$, porém, algumas lesões podem passar despercebidas se houver bloqueio da perfuração pelas alças de intestino delgado ${ }^{4}$. A tomografia computadorizada pode mostrar líquido livre intraperitoneal, apesar de isoladamente não permitir o diagnóstico definitivo.

O tratamento da ruptura intraperitoneal de bexiga é cirúrgico, por meio do desbridamento operatório, rafia da perfuração vesical e lavagem da cavidade abdominal com solução salina a 0,9\%. A laparoscopia é excelente alternativa para o esclarecimento diagnóstico, após a realização dos métodos de imagem e deve ser indicada nos casos de persistente dúvida diagnóstica ${ }^{5}$.

O conhecimento desta grave afecção, com alta taxa de mortalidade (47\%) e a instituição precoce do tratamento operatório são os pré-requisitos para se evitar a indesejável evolução para sepse abdominal e óbito'.

Apesar de doença urológica, os cirurgiões gerais devem ser alertados para a possibilidade da ruptura espontânea de bexiga. Quadros de abdome agudo com dor hipogástrica, infecção e sintomas urinários em pacientes diabéticos ou portadores de neuropatia ou doença vesical, fazem pensar na possibilidade da afecção. O diagnóstico precoce por meio de cistografia ou exploração cirúrgica, podem impedir sua má evolução clínica.

\section{A B S T R A C T}

A case of spontaneous perforation of the bladder in a diabetic female patient is reported. It is a rare clinical condition, that should be suspected in patients with a past history of radiotherapy to the pelvis, enterocystoplasty and those suspected of having a tumor in the bladder. A general surgeon should be aware of this possibility in the differential diagnosis of an acute abdomen.

Key words: Urinary Bladder. Rupture, Spontaneous. Abdomen, acute. Diagnosis, differential.

\section{REFERÊNCIAS}

1. Basavaraj DR, Zachariah KK, Feggetter JGW. Acute abdomen remember spontaneuous perforation of the urinary bladder. J R Coll Surg Edinb. 2001; 46(5):316-7.

2. Rackley R, Vasavada SP, Battino BS. Bladder trauma [Internet]. Omaha: EMedicine; 2004. Available from: http:// www.emedicine.com/med/topic2856.htm

3. Ekuma-Nkama EN, Garg VK, Barayan S. Spontaneous rupture of bladder in a primipara. Ann Saudi Med. 1997; 17(6):646-7.

4. Santucci RA, Mcaninch JW. Bladder injuries: evaluation and management. Braz J Urol. 2000; 26(4):408-14.

5. Platter DL, Vaccaro JP, Nelson LE. Bladder trauma [Internet] Omaha: EMedicine; 2008. Available from: http:// www.emedicine.com/radio/topic81.htm
Recebido em 22/04/2006

Aceito para publicação em 30/06/2006

Conflito de interesse: nenhum

Fonte de financiamento:nenhuma

\section{Como citar este artigo:}

Tassi FR, Figueiredo AA, Gomes CA, Soares Júnior C, Bastos Netto JM. Abdome agudo: ruptura espontânea de bexiga como um importante diagnóstico diferencial. Rev Col Bras Cir. [periódico na Internet] 2009; 36(4). Disponível em URL: http://www.scielo.br/rcbc

\section{Endereço para correspondência:}

Carlos Augusto Gomes

E-mail: caxiaogomes@terra.com.br 